\title{
Challenges of cost-effective high-performance residential construction on the US market: lessons learned from building Utah's most energy-efficient and cost-effective house
}

\author{
J. Rügemer
}

School of Architecture, University of Utah, Salt Lake City, USA

\begin{abstract}
This paper describes the challenges and lessons learned from designing, developing and building the 125 Haus, which is a high performance, passive energy and moderately sized $176 \mathrm{~m}^{2}$ three-bedroom plus studio single-family residential case study project. 125 Haus was built at $2.100 \mathrm{~m}$ elevation at market rate cost in northern Utah's cold climate zone. The building was developed applying an IDP (Integrated Design Process) - a comprehensive, collaborative, interdisciplinary and research-based approach to architecture. The author is the architect and research leader of an interdisciplinary design-build team that included the GC (General Contractor), SE and ME (Structural, Mechanical Engineers) and ITAC (Integrated Technology in Architecture Center). After 125 Haus was completed in October 2011, its construction, energy saving potential, cost efficiency, and ROI (Return on Investment) is now being documented, evaluated and analyzed throughout a two-year post-occupancy monitoring period until fall 2013.

Keywords: high-performance residential buildings, market-transferability of energy-efficient strategies, standard construction and assembly methods, standard building components and materials assemblage of high-performance homes, challenges in residential construction.
\end{abstract}

\section{Introduction}

Design and development process of the 125 Haus has been comprehensively described in earlier reports by Rügemer [1-4]. To become Utah's most Energy- 
Efficient and Cost-Effective House, the following goals had been outlined at the beginning of the design process:

- Functional/multifunctional spaces that allow for compact design and moderate size (approximately $176 \mathrm{~m}^{2}$ conditioned net area);

- Smallest possible impact onto the site;

- Modern and simple design that is rooted in the regional context;

- $\quad 80-90 \%$ efficiency over 2006 IECC code compliant Utah standard;

- Integration of energy simulation to optimize design and passive strategy;

- Minimal, simplified technology;

- Highest possible market-transferability;

- $\quad$ Post-occupancy monitoring to analyze and evaluate actual performance;

- Cost at or below market rate.

Accomplishment of these goals was based on IDP, with an emphasis on a foremost passive design approach that minimized technical and HVAC systems, a strategy that is relatively unknown among the US building industry. To predict building energy performance, evaluate different design strategies, and to identify components and materials, PHPP (Passive House Planning Package) and EPlus (Energy Plus) Energy Modeling software were used during the design phase. $80 \%$ (PHPP) and 90\% (EPlus) efficiency over the code compliant standards was achieved in parallel energy simulations. To account for market-transferability, common construction methods and US available building components and materials were used in 125 Haus' construction. This already allowed for further implementation of some of 125 Haus' passive efficiency measures into the local residential construction market.

The effort to assemble a high-performance building with standard procedures and components created various challenges that show the limits of today's predominant residential construction methods and their applied materials on the US market. Major obstacles and barriers that occurred during construction of this high-performance case study building are described herein.

\section{Team assembly; design and permitting phase}

The author as the A/O (Architect/Owner) concluded a site survey and analysis, a site-specific daylighting study, a code and regional code review, and several meetings with the BD (Building Department) of the jurisdiction. The resulting pre-schematic design was used to communicate the project's idea to potential integrated team members. Challenges of the team assembly phase are also described in earlier reports $[1,4]$; identifying an excellent $\mathrm{GC}$ and $\mathrm{ME}$ at a local market level represented the biggest challenge because many firms were not willing to explore the potential and strategies towards high performance residential buildings in an integrated design process, or to share site and construction responsibilities with the architect during construction. In fact, only one GC was willing to develop the project in an IDP environment; ironically that 
GC was also the most advanced green production builder in the region, offering the most reasonable overall construction cost based on 125 Haus' pre-schematic design description.

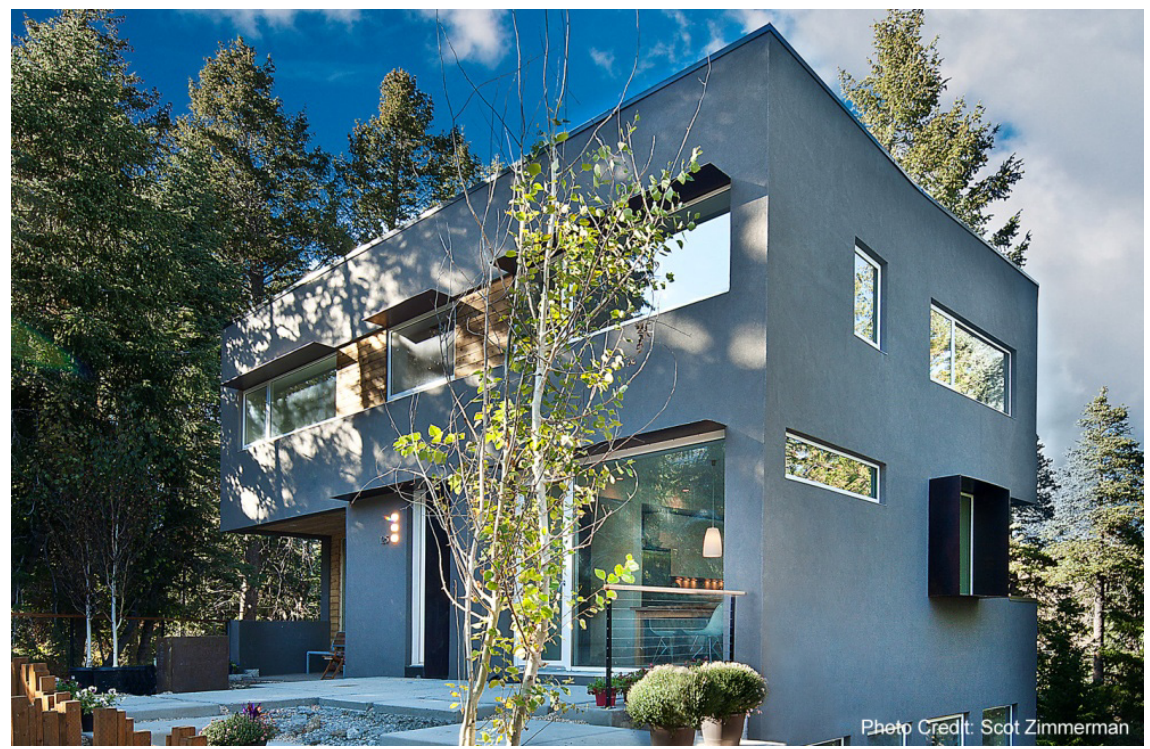

Figure 1: 125 Haus in Park City.

The subsequent design development and construction document phase lasted 8 month, with weekly team meetings between the A/O, GC, and different team members that were present in accordance with their respective tasks. Major nonstandard design steps were checked for code-conformity with the BD. Different construction methods such as SIPs (Structural Insulated Panels), CLT (CrossLaminated Timber), and ICF's (Insulated Concrete Forms) were analyzed and evaluated for their energy- and cost-efficiency. The final decision for a double timber frame construction was based on experience of local work forces, system and assembly costs, and market-transferability. Through intensive, open communication between the team partners, collaboration between the $\mathrm{A} / \mathrm{O}$ and GC was very fruitful, resulting in cost- and energy-efficiency optimized design decisions, material choices, and construction methods. The integration of the $\mathrm{ME}$, who also acted as a sub-contractor for the HVAC system, presented a bigger challenge: ME was unable to openly communicate and to integrate into the team; furthermore he had issues with the low-tech approach that comes with the Passive House strategy. As a result, A/O spent a considerable amount of time to demand smaller systems or to negate them entirely, and to find proper replacement for proposed components that were not required or simply oversized. Communication was limited and one-directional from the A/O-GC to the $\mathrm{ME}$, leading to a series of issues during construction and the final occupancy process. 
Reaching out to firms to receive reliable residential product or service information turned out to be difficult as well, presenting a common issue in the US-residential market segment. Many companies are not used to directly communicate with architects on individual projects, hence the GC often had to slip into this role to receive desired information for the $\mathrm{A} / \mathrm{O}$ on time.

The permitting phase with the BD did not present any serious challenges. The residential plan review included a couple of smaller, code-specific items, with two items worth mentioning:

1. The BD required proper roof ventilation for the attic space. 125 Haus has a highly insulated warm roof without attic that does not require any ventilation. Due to the heavy use of tilted roofs with ventilated attic spaces on the US residential market, it became necessary to educate the inspectors in the function of a flat, non-ventilated warm roof.

2. The low Utah standard code requirements for building envelopes, windows and air infiltration necessitates heating systems with furnaces that are approximately 8-10 times bigger than the systems specified in 125 Haus (Figure 2), which made the BD request an additional written prove from the $\mathrm{ME}$ about the effectiveness of the minimized heating system.

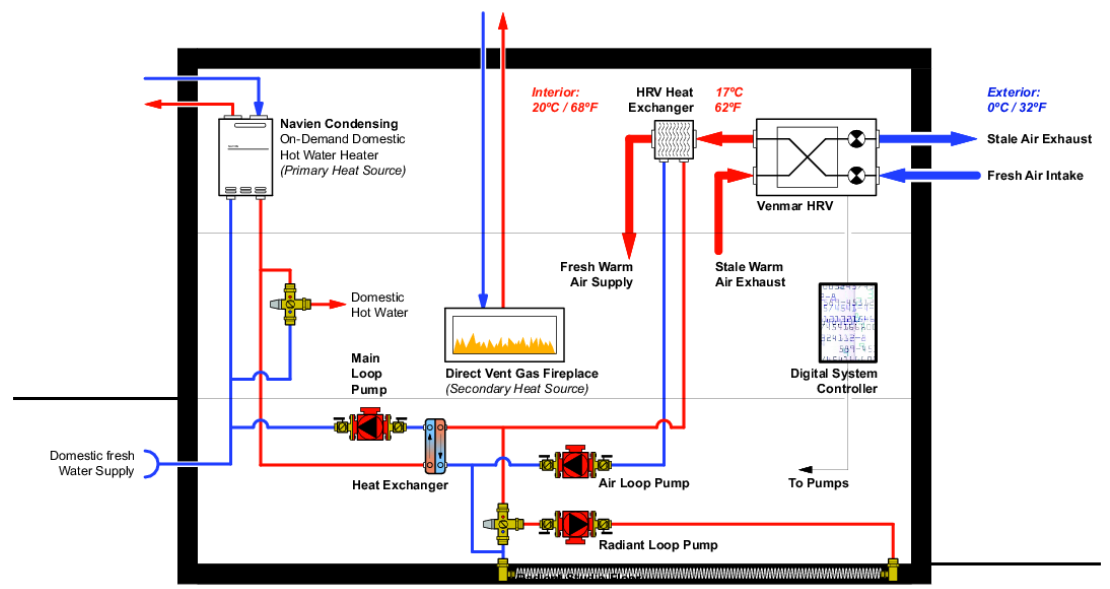

Figure 2: $\quad$ HVAC system diagram.

\section{Financing phase}

With receipt of the building permit in early May 2010, the team was ready to start construction. Due to the financial market situation that year, several attempts to obtain a construction loan failed, causing a subsequent 12-month construction start delay. The first bank, a local Credit Union, needed 8 weeks to process the files, just to find out that they would not give out construction loans any more. The second attempt with a global bank failed due to under-appraisal of the project. The responsible appraisal company was not educated in energyefficient buildings, therefore focusing on visible elements and components that sell, such as large floor areas, three-car garages, granite countertops and other 
items. The real values of a high performance house - compact and functional building form, highly insulated envelope, high performance windows, appliances and systems - were entirely neglected. Furthermore, buildings in the recent loan and mortgage appraisal system are compared to structures being sold in the same location over the past 6-12 months. As a result, 125 Haus was compared to 3035 year old structures of the same size that had literally no energy-efficiency measures in place and were constructed at much lower quality. By the time the $\mathrm{A} / \mathrm{O}$ was notified about the low appraisal, another 6 weeks had been elapsed, and the bank asked to bring an additional $\$ 50,000$ in cash to the table. When a construction loan with a third bank was finally secured by mid August 2010, it was already too late to start construction due to early winters with heavy snowfall at the location. Therefore, the team had to wait until May 2011 to finally start the building's construction.

After finalization of 125 Haus in October 2011, the A/O had to go through a similar process to turn the construction loan into a mortgage. The first appraisal, now for the completed structure, came in unexpectedly low, with the bank instantly offering a very costly mortgage insurance to cover the additional risk. Going with another bank and hiring a different appraiser who was familiar with and trained in high performance buildings, 125 Haus was appraised $\$ 160,000$ higher, all within three weeks after the first appraisal was received. This points out that, in addition to many prejudices that exist towards high performance buildings on the US market, current financing rules and methods provide a big additional obstruction for many clients and firms.

\section{Construction phase}

During construction of 125 Haus, GC and $\mathrm{A} / \mathrm{O}$ shared site administration and responsibilities. This ensured the required level of quality in execution, especially in areas where crews had to specifically be trained. Before starting an assignment, the team met to point out items and (assembly) methods that were particularly important for a high performance structure, such as a low air infiltration rate, assemblage of the walls, thermal bridging and many more.

\subsection{Foundation}

Three items were specifically paid attention to when foundations were installed:

1. A continuous layer of EPS rigid insulation was installed between interior concrete floors and the soil, to minimize thermal bridging. In the conditioned areas of the building, a $10 \mathrm{~cm}$ thick layer of EPS was installed on both sides and all the way down to the strip foundations. The heated concrete floor slab floats on $25 \mathrm{~cm}$ EPS, with the central load-bearing wall of the building resting on $25 \mathrm{~cm}$ Geofoam to avoid any thermal bridging. Geofoam has load-bearing capacities similar to soil, therefore providing an opportunity to insulate foundations entirely from the ground. The garage foundation walls were insulated with $5 \mathrm{~cm}$ EPS and $10 \mathrm{~cm}$ under-slab EPS respectively. 
2. An airtight fit between concrete foundation and stem walls and sill plate had to be guaranteed. Carefully smoothening and leveling the top of the walls overcame this challenge; using a $15 \mathrm{~cm}$ wide EPDM rubber gasket between concrete and sill plate compensated for irregularities (Figure 3). Any remaining gaps between foundation and walls were sealed with acoustical sealant and foam.

3. A radon gas protection layer with over-the-roof exhaust was installed under the floor slab. Plastic sheeting was installed between gravel and under-floor slab insulation, with the edges pulled over the stem and foundations walls to be later covered by the sill plates and gaskets. After the slabs were poured, workers removed the protruding plastic along one side before the A/O could stop them. The defect needed to be hand sealed before the sill plates went in, to ensure proper performance of the system.

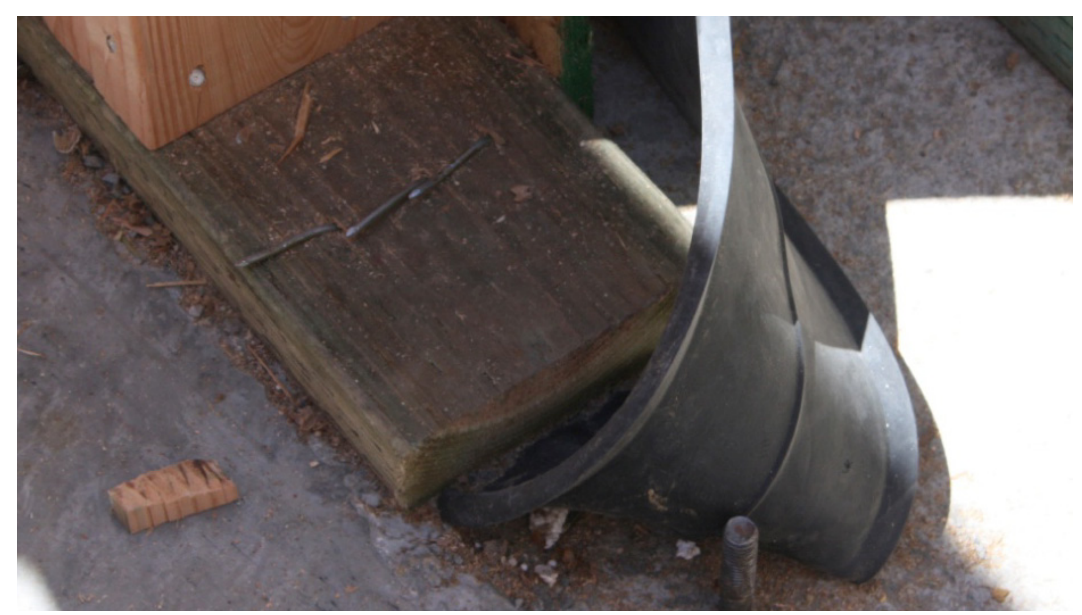

Figure 3: $\quad$ Rubber gasket between sill plate and concrete.

\subsection{Framing}

Due to many components being assembled in the chosen double timber frame EIFS (Exterior Insulated Façade System) wall assembly, the challenges of an airtight building envelope had to be overcome by giving specific care to envelope sealing before the inner BIB (Blown-in Blanket) insulation, drywall, and exterior EIFS were installed. The framing crew was asked to work very precise when installing the sill plates over the rubber gaskets. The structural OSB sheets were glued and sealed with acoustical sealant before being nailed to the frame. Gaps between window and doorframes were sealed with EPDM rubber gaskets and acoustical sealant. Finally, all remaining gaps and cracks in walls and roof were sealed and taped from the outside, with all penetrations for electrical, gas, and plumbing cautiously foam sealed from the inside. 


\subsection{Windows and doors}

High-performance windows and doors with insulated frames were installed as part of the high-performance building envelope. All glass panes were specified to the predominant lighting conditions, orientation, and angle of the sun. Glass quantities were adjusted to the southern orientation, providing larger glazed areas with a higher SHGC (Solar Heat Gain Coefficient) to harvest as much solar energy as possible during cold winter days (SHGC of 0.48 , U-value of $0.16-$ $0.20)$. For the summer, these windows were outfitted with fixed metal sun blades shading the outside to avoid overheating. All windows oriented in other directions are smaller, with a usually lower SHGC of 0.27 (0.49 for some eastfacing units) and U-values of $0.14-0.17$, in combination with a low-emissivity coating and a heat mirror film. Two different US/Canadian window products were chosen, with issues emerging as listed below:

1. Serious Windows insulated fiberglass frame windows, manufactured in the US by Serious Materials, with double pane glazing and heat-mirror Mylar film between the glass panes. Due to the Mylar film, windows and doors have considerable window size restrictions. Right after installation, a few fiberglass frames showed cracks, which negatively influences air infiltration performance. The product came with a new line of gaskets, which in most cases get bruised by the opening mechanism. Although casement window defects are small and might be tolerable, all awning type gaskets were destroyed instantly when opening and closing the window for the first time. Thereafter, air tightness is compromised. The defect was objected right away, but Serious Materials has not been able to solve this very obvious problem; instead the manufacturer blamed the issue on the window installer and finally stopped any communication. For the first winter, the effected windows were sealed temporarily; during the upcoming summer period, the A/O will look for a replacement product. Regional project enquiries among other Serious Windows consumers showed similar product issues throughout many other projects.

2. Cascadia Windows insulated fiberglass frame tilt-turn windows/doors with triple glazing from Canada. The product allows for large, modern window formats on the south facade. All windows and doors were specified and ordered with argon gas filling and PECT (pressure equalizing capillary tubes), which are necessary for pressure equalization when windows are installed at high elevations. Three weeks before delivery, Cascadia communicated that the PECT units could not be filled with argon gas, using air as a replacement. $\mathrm{A} / \mathrm{O}$ was not able to find a replacement product for the windows without considerably delaying the construction schedule. As a result, the four exterior glass doors with smaller glass surfaces have the weakest performance among all doors and windows installed, with U-values of $0.20 \mathrm{Btu} / \mathrm{hr}-\mathrm{ft} 2-^{\circ} \mathrm{F}$ only. 


\subsection{Air infiltration}

Due to the fast pace of construction, and production contractors not being familiar with Passive House requirements, the team needed to invest additional time to seal the building to a final air infiltration rate $0.8 \mathrm{ACH} 50$ or $212 \mathrm{CFM} 50$ after completion. This air infiltration rate left approximately $50 \mathrm{~cm}^{2}$ openings in the entire envelope, which were presumably linear gaps that are difficult to find and seal. Through the process and chosen construction method, A/O learned that the following design decisions created issues with regard to air infiltration performance and insulation:

1. Due to local building height restrictions, the building envelope tilts $5^{\circ}$ in its north and east façades. Those tilts created up to $2 \mathrm{~cm}$ wide, continuous gaps in the façade, which had to be rubber, tape and foam-sealed on the outside. The issue could have possibly been addressed earlier in the process during framing, but at that time the team was not aware of it.

2. Two patio decks were subtracted from the compact building mass; they created considerable challenges due to their complexly framed corners; generally all exterior building corners and deck-to-wall and roof-to-wall connections became hard to seal due to the double stick frame construction, with the inner $2 \times 4$ frame often blocking access to the outer structure and surface. The application of up to $30 \mathrm{~cm}$ Icynene spray-on foam in all critical areas solved the issue well though. In retrospect such details need to be addressed in the construction document phase already, with solutions described to the framer in specific details.

\subsection{Plumbing and electrical}

When it came to exterior skin penetrations that would compromise the required low air-infiltration rate, a considerable lack of knowledge of passive design strategies created general issues with plumbing and electrical trades. Penetrations are simply created by cutting through any surface everywhere, without sealing those openings afterwards; this certainly applied to the natural gas line that was installed after the first blower door test. Those openings had to be foam and tape sealed by $\mathrm{A} / \mathrm{O}$ after the fact, to ensure the proper performance of the envelope. $\mathrm{A} / \mathrm{O}$ also experienced a lack of understanding of economic design. Although the layout of bathrooms, appliances and sinks were designed to reduce the plumbing strand to a minimum, the pipes were installed in a chaotic manner, with a considerable time and cost saving potential lost. A/O expected the logical configuration of all pipes, but learned that a specified plumbing plan has to be delivered even for a small residential project. Warm water pipes were not insulated at all; this work was executed by the $\mathrm{A} / \mathrm{O}$ before the interior insulation was installed.

\subsubsection{Insulation}

Three different systems were applied to highly insulate the building envelope in addition to slab and foundation insulation measures. The importance of proper 
work in this phase required additional quality control by the $\mathrm{A} / \mathrm{O}$, to ensure continuous insulation application throughout the building.

1. An open-cell Icynene spray-on insulation was used in all critical areas of the frame, such as building corners and wall-to-ceiling connections. Concrete walls on the lower floor in direct contact with the soil were also spayfoamed for better insulation value. This contributed to a considerably lower air-infiltration rate.

2. $28 \mathrm{~cm}$ fiberglass $B I B$ insulation was blown into the double stud wall, all ceilings, and into the $40 \mathrm{~cm}$ flat roof cavities. Besides providing for a continuous insulation, this added acoustical comfort within the building. The density of the material was constantly checked to avoid possible future settling. TGI-Joists in the roof had to be installed at $20 \mathrm{~cm}$ on center to accommodate for the high snow load of 100psf; therefore the BIB had to be applied carefully in this critical area. Thermal imagining at a later time showed very satisfying results throughout the entire building.

As part of the EIFS system, a layer of $10 \mathrm{~cm}$ EPS rigid insulation was wrapped around all facades and the roof. The installation crew wanted to use readily available $5 \mathrm{~cm}$ thick material, which would have added complexity and taken more time to install. Alternatively, A/O found a local EPS manufacturer that provided $10 \mathrm{~cm}$ thick boards. A considerable issue emerged when installing the drainage layer behind the EPS: Tyvek provides a special, wrinkled building paper to be installed with the EIFS system. To ensure proper drainage, the paper has to be installed vertically. Despite clear marks on the material, the crew installed the paper in two directions in order to save material (Figure 04). The subcontractor stated that this wouldn't diminish system performance; only after consulting with the manufacturer, the subcontractor changed the direction of the paper where necessary. Accurate installation of any EIFS system is extremely critical to ensure proper performance, especially at a location where the daily exterior façade temperature range can be as large as $90^{\circ} \mathrm{C}$.

3. Conditioned spaces are located above and below the two exterior patios. Due to the building's height restrictions, the effective thickness of insulation is as low as $14 \mathrm{~cm}$ in one case, which was an issue accepted by design. The thermal imaging analysis showed no considerable drop in surface temperature though, averaging $1,5^{\circ} \mathrm{C}$ only (Figure 5).

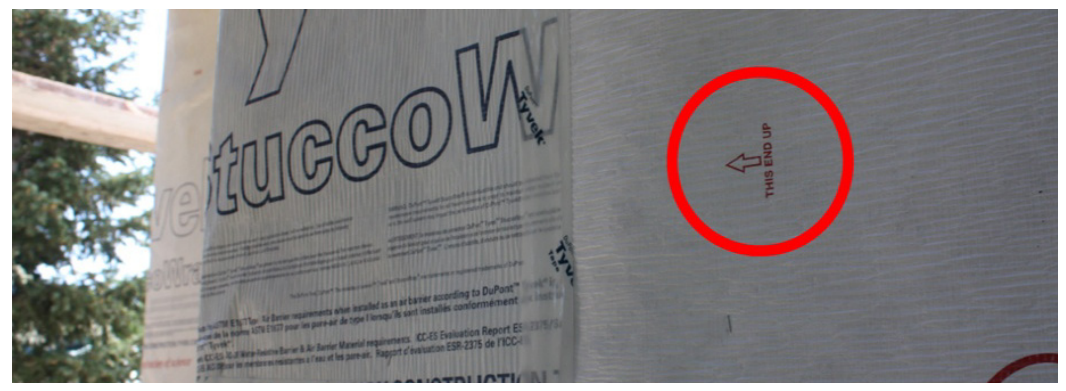

Figure 4: $\quad$ Improperly installed Tyvek. 

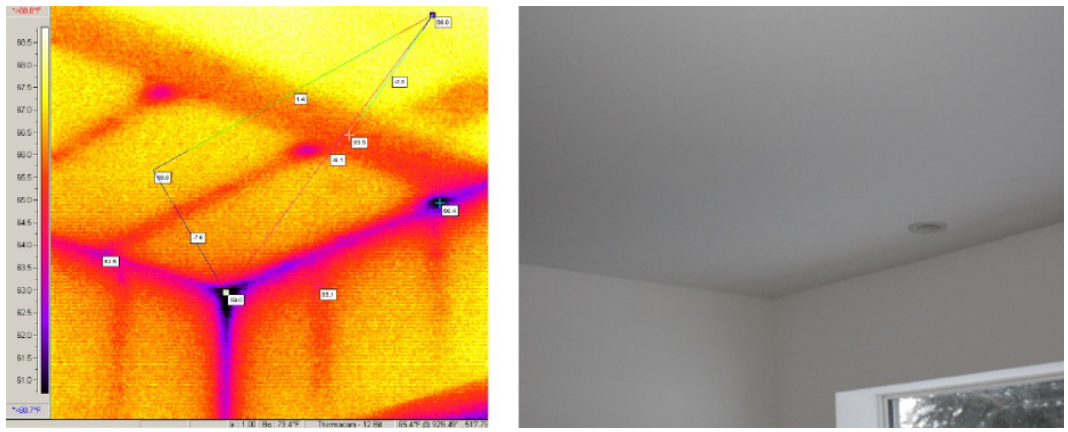

Figure 5: Thermal image of ceiling under deck.

\subsection{HVAC system}

ME's resistance to communicate system decisions to the team throughout the IDL process presented the biggest challenge within the collaborative setting. As a result thereof multiple issues emerged:

1. Although ME claimed to be familiar with the low-tech approach of the Passive House, ME constantly tried to implement bigger, therefore more complex and expensive systems. This continued throughout the design phase well into construction of 125 Haus.

2. ME's EPlus energy simulations are significantly off. Their model showed an annual space heating energy demand of 5.8MBtu/a. As of April 2012, actual annual space heating demand is at approximately $22.6 \mathrm{MBtu} / \mathrm{a}$ (excluding the electric energy to run the system). After analyzing the first 6 months of monitoring results, ME excused this fact by stating that he used incorrect climate data that was based on Salt Lake City International Airport climate at $1.080 \mathrm{~m}$ elevation, instead of applying the correct location at $2.100 \mathrm{~m}$.

3. In contrast to above, ME negated the necessity of an additional heat source in the Master Bathroom that is located in the building's northwest corner. When the bathroom temperature dropped to a constant $17.5^{\circ} \mathrm{C}$ in the first cold month, an additional electrical towel warmer needed to be installed.

4. ME could not keep up with the pace of construction, generating scheduling issues throughout the construction phase.

5. ME performed the first blower door test before insulation installation. The same crew returned a week later to install the HRV and gas water heater ductwork. The penetrations to the exterior were not sealed, adding approximately $70 \mathrm{~cm}^{2}$ gaps to the already tightly sealed and insulated envelope. The defect was carefully hidden inside the BIB and EPS insulation; it became obvious only after some exterior EPS boards were exchanged for wooden siding in the area of the exhausts pipes. The issue needed to be fixed by $\mathrm{A} / \mathrm{O}$; ME did not respond in any way.

6. ME took the remote control for the on-demand hot water heater, disabling the occupants to adjust the temperature to the exterior conditions during the 
very cold winter months. After detecting the issue, A/O ordered a new part directly from the manufacturer to ensure proper system performance.

7. $\mathrm{ME}$ is not able to properly configure and program the digital system controller. As a result, about $10 \%$ of the monthly monitoring temperature data gets lost; the system needs to be run manually at times because the controller shuts down or turns on the system for no specific reason, which has a negative impact on the overall energy consumption. Several attempt to fix the issue failed. Investigations show that comparable installations in other buildings by the ME illustrate similar challenges.

8. Due to a delayed installation of the HVAC system and literally no communication between ME and building inspector, a misarranged HVAC system caused the inspector to not grant the certificate of occupancy. The system had to be spatially reconfigured, which added extra cost and resulted in a 2 -week delay in obtaining the final certification.

\subsection{Inspections}

Some difficulties arouse through building officials not being educated in the Passive House concept, similar to the earlier described heating system issue during the permitting phase. More difficulties were added through a building inspector who didn't communicate foresighted and instead waited for items to be finalized. Issues that could have been addressed at early stages where objected too late, causing extra cost and delays. Some objections about items that were actually built to code were not justified at all, or weren't addressed in the plan review, but a Utah building inspector has authority about final decisions. Overall the collaboration with the building officials worked well during the permitting phase, but became questionable during construction inspections. In summary, there is an urgent need to educate building authorities, inspectors, and other building professionals in the design and execution of high performance residential buildings.

\section{Conclusion}

In summary the integrated design and construction experience has been mostly satisfying for nearly all team members. The chosen IDP process was essential to achieve the goals of energy-efficiency and cost-effectiveness. The first 7 months of occupancy and monitoring showed that 125 Haus is performing mostly to its promises. With winter nighttime temperatures down to $-20^{\circ} \mathrm{C}$, the house kept its interior temperature well, losing only $3-5^{\circ} \mathrm{C}$ overnight in very cold nights with all systems generally turned off at nighttime. On sunny winter days, the passive solar heat gain heats the house throughout the day, with the gas fireplace turned on for approximately 60-90 minutes in the early morning hours. No heating is necessary when minimum nighttime temperatures are above $-5^{\circ} \mathrm{C}$ and the sun shines throughout the day. During overcast skies and stormy periods, the instant hot water heater and gas fireplace provide for necessary heating. With reinstallation of the remote control for the on-demand hot water heater, occupants 
are now able to adjust primary water temperatures up to $60^{\circ} \mathrm{C}$ for very cold periods, which will make the system work more efficient. Based on the data collected so far, estimated expenses for natural gas and electricity to heat the building and run the HRV system are at \$24.52/month average, or \$294/year; this compares to an anecdotally reported $\$ 400$ per single winter month for natural gas only for standard buildings in the same neighborhood. Final numbers will be available after a full one-year cycle of monitoring. Final construction cost came in at $\$ 282,600$. This breaks down to $\$ 117.75 /$ square feet conditioned gross area (approx. $960 € / \mathrm{m}^{2}$ ), excluding cost for land, impact and design fees, and compares to $\$ 115 /$ square feet or 276,000 overall cost for a comparable, built to code house in the same location. Based on a conservative energy cost saving projection of $\$ 1,200 /$ year, the difference of roughly $\$ 6,600$ will pay back within $51 / 2$ years. Lending this extra money at recent loan rates of $4 \%$ would raise the monthly mortgage payments about $\$ 25$ only, with immediate monthly energy saving cost of $\$ 100$. This produces an instant positive cash flow.

\section{References}

[1] Rügemer, J. Design Strategies Towards High Performance Market Rate Housing: the 125 Haus in Utah, The International Journal of Design Principles and Practices, Volume 5, Issue 5: Champaign, Illinois, pp. 253276, 2011.

[2] Rügemer, J. Architectural Design for Energy-Efficient and Cost-Effective Buildings in Cold Climate Zones, Proceedings of the 6th Energy Forum on Solar Building Skins: Bressanone, Italien, pp. 149-153, 2011.

[3] Rügemer, J. Energy-Efficient and Cost-Effective Residential Passive House Design in the Utah Cold Climate Zone, Proceedings of the Building Enclosure Sustainability Symposium: Pomona, CA, pp. 157-172, 2011.

[4] Rügemer, J. The Introduction of Sustainable Strategies and Technology to the US Housing Building Industry - Design, Construction and Performance Analysis of Energy Efficient Residential Buildings - A Case Study, The International Journal of Technology, Knowledge and Society, Volume 6: Champaign, Illinois, pp. 150-161, 2010. 